American J. of Engineering and Applied Sciences 1 (4): 287-294, 2008

ISSN 1941-7020

(C) 2008 Science Publications

\title{
Water Hammer Analysis by Characteristic Method
}

\author{
${ }^{1}$ A.R. Lohrasbi and ${ }^{2}$ R. Attarnejad \\ ${ }^{1}$ MSc Civil Engineering, School of Civil Engineering, University of Tehran, Tehran Iran \\ ${ }^{2}$ Faculty Member, School of Civil Engineering, University of Tehran, Tehran, Iran
}

\begin{abstract}
Rapid changes in the velocity of fluid in closed conduits generate large pressure, which are transmitted through the system with the speed of sound. When the fluid medium is a liquid the pressure surges and related phenomena are described as water hammer. Water hammer is caused by normal operation of the system, such as valve opening or closure, pump starts and stoppages and by abnormal condition, such as power failure. Problem statement: Water hammer causes the additional pressure in water networks. This pressure maybe defects on pipes and connections. The likely effects of water hammer must be taken into account in the structural design of pipelines and in the design of operating procedures for pumps, valves, etc. Approach: The physical phenomena of water hammer and the mathematical model which provides the basis for design computations are described. Most water hammer analysis involves computer solution by the method of characteristics. In this study water hammer is modelled with this method and effect of valve opening and closure will be surveyed with a program that is used for this purpose and with a numerical example. Results: The more rapid the closure of the valve, the more rapid is the change in momentum and hence, greater is the additional pressure developed. Conclusions/Recommendations: For preventing of water hammer defects, is recommended that valves should be open or closed slowly. Also with using the method of characteristics, we can modelled all pipe networks, and see the affects of water hammer.
\end{abstract}

Key words: Water hammer, fluid, velocity, rapid change, characteristics method, valve

\section{INTRODUCTION}

Water hammer suddenly changes in the velocity of fluid in a closed conduit, which is flowing full cause surges of pressures, which are propagated through the system with the speed of sound. This is the case whether the fluid is liquid or gas. When the fluid is a liquid, the pressure surges and related phenomena are described as water hammer. When, for example, the velocity of flow in a pipe is suddenly reduced, kinetic energy is converted into potential energy as the pressure increases, the liquid is compressed and the pipe wall is stretched. The disturbances so produced travel up and down the pipeline as water hammer waves. The changes in velocity can be caused by a wide range of disturbances such as valve operation, pump operation, turbine governing and so on. The roost common circumstances which give rise to water hammer of engineering significance are those associated with pumps; normal starting and stopping of pumps and stoppages caused by power failure. In the design of pipe systems it is necessary to take into account the magnitudes of pressure surges associated with water hammer phenomena and, consequently, it is important that these water hammer effects be calculated with the appropriate accuracy.
Governing Equation of water hammer: Application of Newton's second law of motion to the case of unsteady flow of a compressible liquid in an elastic pipe leads ultimately to the momentum Equation,

$$
\mathrm{g} \frac{\partial \mathrm{H}}{\partial \mathrm{x}}+\frac{\mathrm{f}}{2 \mathrm{D}} \mathrm{V}|\mathrm{V}|+\mathrm{V} \frac{\partial \mathrm{V}}{\partial \mathrm{x}}+\frac{\partial \mathrm{V}}{\partial \mathrm{t}}=0
$$

From considerations of conservation of matter, the continuity Equation is obtained in the form,

$$
\frac{\mathrm{a}^{2}}{\mathrm{~g}} \frac{\partial \mathrm{V}}{\partial \mathrm{x}}+\mathrm{V}\left(\frac{\partial \mathrm{H}}{\partial \mathrm{x}}+\sin \alpha\right)+\frac{\partial \mathrm{H}}{\partial \mathrm{t}}=0
$$

In Eq. 1 and 2, $\mathrm{H}$ denotes the piezometric head at the centreline of the pipeline at location $\mathrm{x}$ and time $\mathrm{t}, \mathrm{V}$ is the average velocity of flow, $\mathrm{D}$ is the pipe diameter, $\mathrm{f}$ is the friction factor in the Darcy-Weisbach formula, $\mathrm{x}$ is the distance along the centreline of the pipe, $\alpha$ is the angle between the horizontal and the centreline of the pipe, taken as positive for the pipe sloping downwards in the direction of positive $\mathrm{x}, \mathrm{g}$ is the gravitational constant; and a is the celerity of the pressure surge, i.e. the velocity with which the surge is propagated relative to the liquid. The positive direction for $\mathrm{V}$ coincides with that for $\mathrm{x}$.

The Eq. 1 and 2 are a simultaneous pair of partial differential Equations which relate the two dependent 
variables, $\mathrm{H}$ and $\mathrm{V}$, as functions of $\mathrm{x}$ and $\mathrm{t}$. All methods of analysis of water hammer have these Equations, or simplified forms of them, as their starting point and it is important to note the assumptions and approximations which have been used in their derivation. These are as follows:

- The velocity and pressure are assumed uniform across the pipe, i.e., a one-dimensional model is used

- The pipe is full of liquid at all times

- The effects of changes in velocity head are neglected

- In Eq. 1 the effects of variation in density of the liquid are treated as negligible

- It is assumed that friction factors obtained under steady conditions apply to unsteady flows

The restrictions listed above cause only slight errors of the order of $0.1 \%$ in the normal engineering situation, except for (ii). If cavitation or separation of the water column does occur as a consEq.uence of water hammer effects, this must be accounted for specifically as an extra internal condition to be satisfied.

The wave celerity, a, is evaluated from the expression:

$$
\mathrm{a}=\left(\frac{\mathrm{K}}{\rho}\right)^{0.5}\left(1+\frac{\mathrm{K}}{\mathrm{E}} \frac{\mathrm{D}}{\mathrm{e}} \mathrm{C}_{1}\right)^{-0.5}
$$

In which $\mathrm{K}$ is the bulk modulus of the liquid in the pipe, $\rho$ is the density of the liquid, $E$ is young's modulus and $\mu$ is Poison's ratio of the pipe wall material, e is the Eq.uivalent thickness of the pipe wall and $\mathrm{C} 1$ is a factor which accounts for different conditions of restraint of the pipe. The types of axial restraint commonly encountered are:

Case a: The pipe is restrained throughout its length against axial movement,

$$
\mathrm{C}_{1}=1-\mu^{2}
$$

Case b: The pipe has frEq.uent expansion joints throughout its length,

$$
\mathrm{C}_{1}=1
$$

Case a, the pipe is restrained at its upstream end only,

$$
\mathrm{C}_{1}=\frac{5}{4}-\mu
$$

In most engineering applications case $\mathrm{a}$ or $\mathrm{b}$ or some condition intermediate between them would apply. For the case of water in a steel pipe,

$$
\mathrm{a}=1438\left(1+0.01 \frac{\mathrm{D}}{\mathrm{e}} \mathrm{C}_{1}\right)^{-0.5}
$$

In the derivation of the expression for a, Eq. 3, a further assumption is introduced in addition to those already listed. This involves the neglect of the interaction between the propagation of elastic stress waves in the pipe wall and of the pressure surges in the liquid. This approximation can cause significant errors in the evaluation of water-hammer effects for rapid velocity changes in some circumstances. For slower operations the effects of the approximation seem not to be significant. It is worth noting that, for Case $b$ above, there is no approximation involved.

Characteristic relations of governing Equation: The pair of partial differential Equations 1 and 2 are of hyperbolic type and, consEq.uently, linear combinations of them can be found which reduce to ordinary differential Equations along two intersecting families of curves in the $\mathrm{x}$, t-plane. The Equations which specify the two families of curves and the ordinary differential relationships along them are described as the characteristic relations of the Eq. 1 and 2. To obtain the characteristic relations we add to Eq. 1 the 2 multiplied by $\lambda$ to give,

$$
\begin{aligned}
& \lambda\left[\frac{\partial \mathrm{H}}{\partial \mathrm{t}}+\left(\mathrm{V}+\frac{\mathrm{g}}{\lambda}\right) \frac{\partial \mathrm{H}}{\partial \mathrm{x}}\right]+\left[\frac{\partial \mathrm{V}}{\partial \mathrm{t}}+\left(\mathrm{V}+\frac{\mathrm{a}^{2}}{\mathrm{~g}} \lambda\right) \frac{\partial \mathrm{V}}{\partial \mathrm{x}}\right]+ \\
& \lambda \mathrm{V} \sin \alpha+\frac{\mathrm{f}}{2 \mathrm{D}} \mathrm{V}|\mathrm{V}|=0
\end{aligned}
$$

Since $\mathrm{H}$ and $\mathrm{V}$ are functions of $\mathrm{x}$ and $\mathrm{t}$, their total derivatives can be expanded as,

$$
\frac{\mathrm{dH}}{\mathrm{dt}}=\frac{\partial \mathrm{H}}{\partial \mathrm{t}}+\frac{\partial \mathrm{H}}{\partial \mathrm{x}} \frac{\mathrm{dx}}{\mathrm{dt}} ; \frac{\mathrm{dV}}{\mathrm{dt}}=\frac{\partial \mathrm{V}}{\partial \mathrm{t}}+\frac{\partial \mathrm{V}}{\partial \mathrm{x}} \frac{\mathrm{dx}}{\mathrm{dt}}
$$

Consequently, the Eq. 4 can be rewritten as the ordinary differential Equation,

$$
\lambda \frac{\mathrm{dH}}{\mathrm{dt}}+\frac{\mathrm{dV}}{\mathrm{dt}}+\lambda \mathrm{V} \sin \alpha+\frac{\mathrm{f}}{2 \mathrm{D}} \mathrm{V}|\mathrm{V}|=0
$$

If and, only if, $\lambda$ satisfied the relations,

$$
\mathrm{V}+\frac{\mathrm{g}}{\lambda}=\frac{\mathrm{dx}}{\mathrm{dt}}=\mathrm{V}+\frac{\mathrm{a}^{2}}{\mathrm{~g}} \lambda
$$

i.e.,

$$
\lambda= \pm \frac{\mathrm{g}}{\mathrm{a}}
$$

For each of the two values of $\lambda$ given by Eq. 8 there are two distinct values of $\mathrm{dx} / \mathrm{dt}$ Eq. 7 and these provide the equations to the curves in the $\mathrm{x}$, t-plane along which the ordinary differential Eq. 6 valid. Substitution of the two values of $\lambda$ from Eq. 8 into 6 and 7 produces the set of characteristic relations of the Eq. 1 and 2viz,

$$
\frac{\mathrm{g}}{\mathrm{a}} \frac{\mathrm{dH}}{\mathrm{dt}}+\frac{\mathrm{dV}}{\mathrm{dt}}+\mathrm{V}|\mathrm{V}| \frac{\mathrm{f}}{2 \mathrm{D}}+\frac{\mathrm{g}}{\mathrm{a}} \mathrm{V} \sin \alpha=0
$$

Along the direction,

$$
\frac{\mathrm{dx}}{\mathrm{dt}}=\mathrm{V}+\mathrm{a}
$$


and

$$
-\frac{\mathrm{g}}{\mathrm{a}} \frac{\mathrm{dH}}{\mathrm{dt}}+\frac{\mathrm{dV}}{\mathrm{dt}}+\mathrm{V}|\mathrm{V}| \frac{\mathrm{f}}{2 \mathrm{D}}-\frac{\mathrm{g}}{\mathrm{a}} \mathrm{V} \sin \alpha=0
$$

Along the direction,

$$
\frac{\mathrm{dx}}{\mathrm{dt}}=\mathrm{V}-\mathrm{a}
$$

The Eq. 9-12 are Equal t to the Eq. 1 and 2 and solutions of Eq. 9-12 are solutions of Eq. 1 and 2. The method of solution which uses the characteristic relations is called the method of characteristics. In essence, in the method of characteristics one sets out to find the two intersecting families of curves corresponding to Eq. 10 and 12 and integrates the Eq. 9 and 11 along these curves to produce values of $\mathrm{H}$ and $\mathrm{V}$ at the $(x, t)$ coordinates which are the intersections of the curves. The process is illustrated schematically in Fig. 1. The curves labelled $\mathrm{C}^{+}$correspond to Eq. 10 and those labelled $\mathrm{C}^{-}$correspond to Eq. 12. For a solution to be calculated initial conditions must be known for all points and boundary conditions must be specified at each end of the pipe for all time. Types of boundary conditions encountered are numerous, but ail can be expressed ultimately as a relationship between $\mathrm{H}$ and $\mathrm{V}$ at the ends of the pipe.

The characteristic relations bring out clearly the physical significance of the parameter, a, which denotes the celerity of the water hammer waves. They describe mathematically the physical phenomena, which consist of disturbances travelling in both directions in the pipe and causing changes in the velocity and the pressure. The Eq. 9 and 10 describe a wave which travels in the downstream direction with a velocity a, relative to the liquid, as defined by Eq. 10 and which causes changes in $\mathrm{H}$ and $\mathrm{V}$ defined by Eq. 9. Similarly, Eq. 11 and 12 describe a wave which travels in the upstream direction with a velocity a relative to the liquid, as defined by Eq. 12 and which causes changes $\mathrm{H}$ and $\mathrm{V}$ defined by Eq. 11.

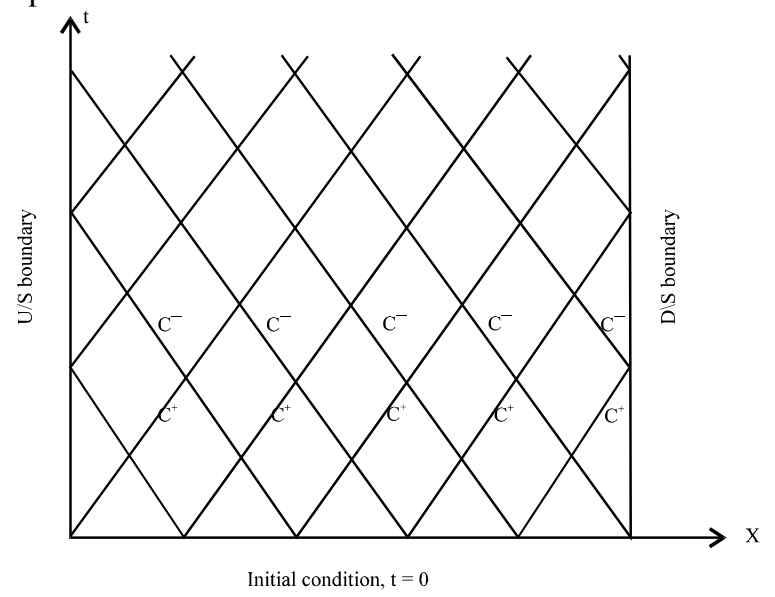

Fig. 1: Families of characteristic curves

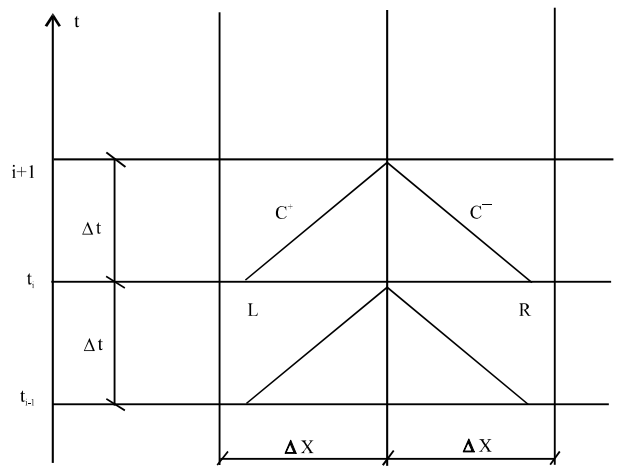

Fig. 2: Computational grid

Computer solution by method of characteristics: In this section the method for integrating numerically the characteristic relations of the full Equations, called the method of specified time intervals is presented. In this method, values of $\mathrm{H}$ and $\mathrm{V}$ are calculated at regular intervals in $\mathrm{x}$ and $\mathrm{t}$, as illustrated in Fig. 2. The curves labelled $\mathrm{C}^{+}$and $\mathrm{C}^{-}$correspond to the curves defined by Eq. 10 and 12 , respectively.

The finite difference approximations to the characteristic relations used are:

$$
\begin{aligned}
& \frac{g}{a}\left(H_{i}^{n+1}-H_{L}\right)+\left(V_{i}^{n+1}-V_{L}\right)+\frac{g}{a} V_{L} \sin \alpha \\
& +V_{L}\left|V_{L}\right| \frac{f}{2 D} \Delta t+o(\Delta t)^{2}=0 \\
& x_{i}-x_{L}=\left(V_{L}+a\right) \Delta t+o(\Delta t)^{2}
\end{aligned}
$$

and

$$
\begin{aligned}
& -\frac{g}{a}\left(H_{i}^{n+1}-H_{R}\right)+\left(V_{i}^{n+1}-V_{R}\right)-\frac{g}{a} V_{R} \sin \alpha \\
& +V_{R}\left|V_{R}\right| \frac{f}{2 D} \Delta t+o(\Delta t)^{2}=0 \\
& x_{i}-x_{R}=\left(V_{R}+a\right) \Delta t+o(\Delta t)^{2}
\end{aligned}
$$

In the finite difference Eq.uitation;

$$
\mathrm{H}_{\mathrm{i}}^{\mathrm{n}+1}=\mathrm{H}\left(\mathrm{x}_{\mathrm{i}}, \mathrm{t}_{\mathrm{n}+1}\right)=\mathrm{H}\left[\mathrm{x}_{0+1} \Delta \mathrm{x}, \mathrm{t}_{0}+(\mathrm{n}+1) \Delta \mathrm{t}\right]=0
$$

If the higher order terms are neglected, The Eq. 9a, 11a can be written as,

$$
\begin{aligned}
& \frac{\mathrm{g}}{\mathrm{a}} \mathrm{H}_{\mathrm{i}}^{\mathrm{n}+1}+\mathrm{V}_{\mathrm{R}}^{\mathrm{n}+1}=\phi_{\mathrm{L}} \\
& -\frac{\mathrm{g}}{\mathrm{a}} \mathrm{H}_{\mathrm{i}}^{\mathrm{n}+1}+\mathrm{V}_{\mathrm{R}}^{\mathrm{n}+1}=\phi_{\mathrm{R}}
\end{aligned}
$$

Where,

$$
\phi_{\mathrm{L}}=\frac{\mathrm{g}}{\mathrm{a}} \mathrm{H}_{\mathrm{L}}+\mathrm{V}_{\mathrm{L}}-\frac{\mathrm{g}}{\mathrm{a}} \mathrm{V}_{\mathrm{L}} \sin \alpha \Delta \mathrm{t}-\mathrm{V}_{\mathrm{L}}\left|\mathrm{V}_{\mathrm{L}}\right| \Delta \mathrm{t}
$$




$$
\phi_{\mathrm{R}}=-\frac{\mathrm{g}}{\mathrm{a}} \mathrm{H}_{\mathrm{R}}+\mathrm{V}_{\mathrm{R}}+\frac{\mathrm{g}}{\mathrm{a}} \mathrm{V}_{\mathrm{R}} \sin \alpha \Delta \mathrm{t}-\mathrm{V}_{\mathrm{R}}\left|\mathrm{V}_{\mathrm{R}}\right| \Delta \mathrm{t}
$$

The values of $\mathrm{V}$ and $\mathrm{H}$ at $\mathrm{L}$ and $\mathrm{R}$ are expressed in terms of the values of these quantities at regular grid points by linear interpolation and use of the Eq. 10a, 12a to give the expressions;

$$
\begin{aligned}
& \mathrm{V}_{\mathrm{L}}=\frac{\mathrm{V}_{\mathrm{i}}^{\mathrm{n}}-\mathrm{a}\left(\mathrm{V}_{\mathrm{i}}^{\mathrm{n}}-\mathrm{V}_{\mathrm{i}-1}^{\mathrm{n}}\right) \Delta \mathrm{t} / \Delta \mathrm{x}}{1+\left(\mathrm{V}_{\mathrm{i}}^{\mathrm{n}}-\mathrm{V}_{\mathrm{i}-1}^{\mathrm{n}}\right) \Delta \mathrm{t} / \Delta \mathrm{x}} \\
& \mathrm{H}_{\mathrm{L}}=\mathrm{H}_{\mathrm{i}}^{\mathrm{n}}-\left(\mathrm{V}_{\mathrm{L}}+\mathrm{a}\right)\left(\mathrm{H}_{\mathrm{i}}^{\mathrm{n}}-\mathrm{H}_{\mathrm{i}-1}^{\mathrm{n}}\right) \Delta \mathrm{t} / \Delta \mathrm{x}
\end{aligned}
$$

and

$$
\begin{aligned}
& \mathrm{V}_{\mathrm{R}}=\frac{\mathrm{V}_{\mathrm{i}}^{\mathrm{n}}-\mathrm{a}\left(\mathrm{V}_{\mathrm{i}}^{\mathrm{n}}-\mathrm{V}_{\mathrm{i}-1}^{\mathrm{n}}\right) \Delta \mathrm{t} / \Delta \mathrm{x}}{1-\left(\mathrm{V}_{\mathrm{i}}^{\mathrm{n}}-\mathrm{V}_{\mathrm{i}-1}^{\mathrm{n}}\right) \Delta \mathrm{t} / \Delta \mathrm{x}} \\
& \mathrm{H}_{\mathrm{R}}=\mathrm{H}_{\mathrm{i}}^{\mathrm{n}}+\left(\mathrm{V}_{\mathrm{R}}-\mathrm{a}\right)\left(\mathrm{H}_{\mathrm{i}}^{\mathrm{n}}-\mathrm{H}_{\mathrm{i}-1}^{\mathrm{n}}\right) \Delta \mathrm{t} / \Delta \mathrm{x}
\end{aligned}
$$

The Eq. 9b, 11b and 13 through 16 provide the algorithm for advancing the calculations of water hammer transients from known conditions at th to the

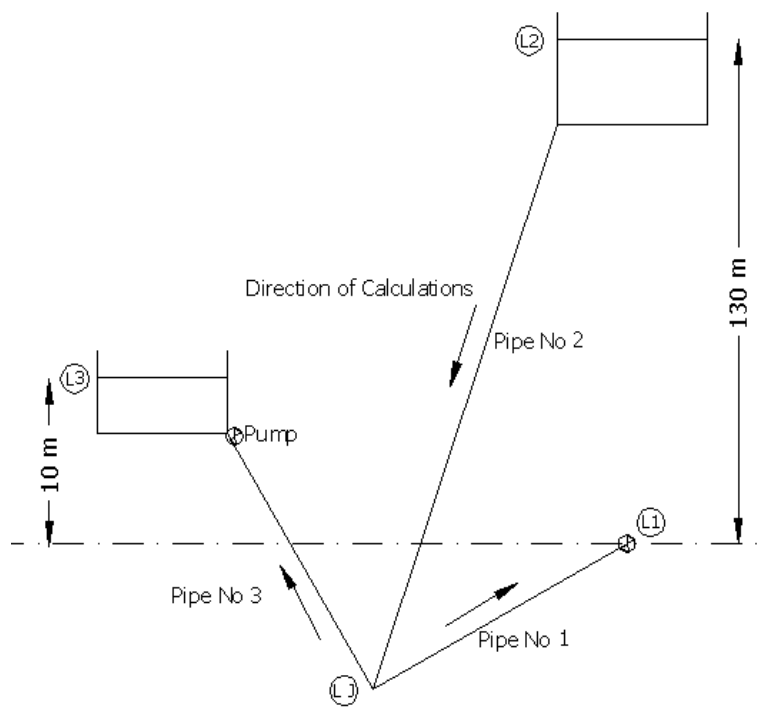

Fig. 3: Numerical example

new time $\operatorname{tn}+1$. For an interior point in a length of uniform pipe, the Eq. $9 \mathrm{~b}$ and $11 \mathrm{~b}$ give simply,

$$
\mathrm{V}_{\mathrm{i}}^{\mathrm{n}+1}=0.5\left(\phi_{\mathrm{L}}+\phi_{\mathrm{R}}\right)
$$

And

$$
\mathrm{H}_{\mathrm{i}}^{\mathrm{n}+1}=0.5\left(\phi_{\mathrm{L}}-\phi_{\mathrm{R}}\right) \mathrm{a} / \mathrm{g}
$$

At each end of a length of uniform pipe only one of the Eq. $9 \mathrm{~b}, 11 \mathrm{~b}$ is available the first at the downstream end and the second at the upstream end. The second Equation needed to compute $\mathrm{V}$ and $\mathrm{H}$ at end points is provided by the boundary conditions at the pipe ends, which will involve $\mathrm{V}$ or $\mathrm{H}$ or a relation between them.
Numerical example: We want to survey the water hammer effect in this example that involve of two reservoirs, one valve and one pump which works in $\mathrm{t}=$ 6 sec. with characteristic curve $\left(H=a_{\circ}+a_{1} Q+a_{2} Q^{2}\right)$ (Fig 3).

The specifications of pipes are shown in Table 1 .

The specifications of pump and levels of pipe are shown in Table 2.

Table 1: The pipes specifications;

\begin{tabular}{llllll}
\hline Pipe & $\mathrm{L}(\mathrm{cm})$ & $\mathrm{D}(\mathrm{cm})$ & $\mathrm{e}$ & $\mathrm{f}$ & Restrained \\
\hline 1 & 4500 & 250 & 5 & 0.021 & - \\
2 & 2400 & 220 & 5 & 0.026 & Full \\
3 & 1800 & 330 & 5 & 0.018 & Full \\
\hline
\end{tabular}

Table 2: The specifications of pump and levels of pipe;

\begin{tabular}{lllll} 
a0(pump) & a1(pump) & a2(pump) & $\beta$ & $\rho$ \\
\hline 240 & 20 & -300 & 0.212 & 10 \\
H L1(m) & H L2(m) & H L3(m) & H LJ(m) & R \\
0 & 130 & 10 & -10 & 105 \\
\hline
\end{tabular}

- Initial condition

At the start time, there is not any flow in pipe number 3, because the pump hasn't started yet. So in any part of pipe number 3 , velocity is $0(\mathrm{~V}=0)$. Also water head in this pipe is the head of intersection joint (Point J). Water comes from top reservoir and detour to pipe land eject from valve.

In $t=0, \tau=1$ means the valve is open.

Thus, Bernoli Equation between L2 and L1 is 17,

$$
\begin{aligned}
& Z_{L 2}= Z_{L 1}+\sum h_{1}+\frac{V_{1}^{2}}{2 g}=Z_{L 1}+\frac{f_{1} l_{1}}{D_{1}} \frac{V_{1}^{2}}{2 g}+\frac{f_{2} l_{2}}{D_{2}} \frac{V_{2}^{2}}{2 g}+\frac{V_{1}^{2}}{2 g} \\
& 130=0+\frac{.026 * 2400 * 1000}{220} * \frac{V_{2}^{2}}{2 * 9.81}+ \\
& \frac{.021 * 4500 * 1000}{250} * \frac{V_{1}^{2}}{2 * 9.81}+\frac{V_{1}^{2}}{2 * 9.81}
\end{aligned}
$$

Finally,

$$
130=15.90 \mathrm{~V}_{2}^{2}+19.32 \mathrm{~V}_{1}^{2}
$$

with continuity Eq.,

$\mathrm{V}_{1} \mathrm{~A}_{1}=\mathrm{V}_{2} \mathrm{~A}_{2} \Rightarrow \mathrm{V}_{1} * 250^{2}=\mathrm{V}_{2} * 220^{2} \Rightarrow \mathrm{V}_{2}=1.29 \mathrm{~V}_{1}$

From two pervious Eq. 19, 20,

$$
\mathrm{V}_{1}=1.685 \mathrm{~m} / \mathrm{s}, \mathrm{V}_{2}=2.174 \mathrm{~m} / \mathrm{s}
$$

In finite difference, we must to divide length of pipe for calculation. We choose $\Delta x=300 \mathrm{~m}$.

Then in pipe 2 for any location with using Eq. 19 and 20 head and velocity will be calculated;

Also, for pipe 1,

Top outputs are our initial conditions in $\mathrm{t}=0$.

$\mathrm{A}$ in the wave velocity in pipes, 
From Eq. 3:

- $\quad$ Pipe 1 is not Restrained then $\mathrm{C} 1=1$ and $\mathrm{a} 1=1174$

- $\quad$ Pipe 2 is Restrained then $\mathrm{C} 1=0.91$ and $\mathrm{a} 1=1181$

- $\quad$ Pipe 3 is Restrained then $\mathrm{C} 1=0.91$ and $\mathrm{a} 1=1195$

$$
\overline{\mathrm{a}}=\left(\mathrm{a}_{1}+\mathrm{a}_{2}+\mathrm{a}_{3}\right) / 3=1183 \mathrm{~m} / \mathrm{s}
$$

Table 3:;

\begin{tabular}{llllllllll}
\hline $\mathrm{X}$ & 0 & 300 & 600 & 900 & 1200 & 1500 & 1800 & 2100 & 2400 \\
\hline $\mathrm{H}$ & 130 & 120.6 & 111.2 & 101.8 & 92.4 & 83 & 73.6 & 64.2 & 54.8 \\
$\mathrm{~V} 2$ & 2.17 & 2.17 & 2.17 & 2.17 & 2.17 & 2.17 & 2.17 & 2.17 & 2.17 \\
\hline
\end{tabular}

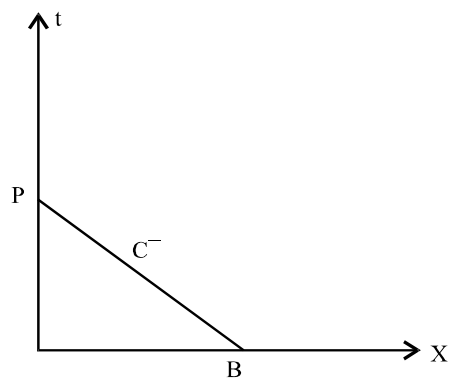

Fig. 4: Upstream boundary conditions

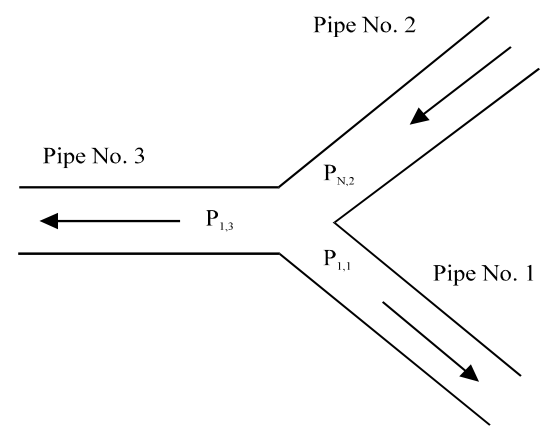

Fig. 5: Pipe intersection

$$
\Delta \mathrm{t}=\frac{\mathrm{L}}{\mathrm{aN}}=\frac{1800}{1183 * 6}=0.254 \mathrm{Sec} \Rightarrow \Delta \mathrm{t}=0.25 \mathrm{Sec}
$$

Curant number must be less than 1 ,

$$
\mathrm{C}_{\mathrm{r}}=\frac{\mathrm{a} \Delta \mathrm{t}}{\Delta \mathrm{x}}=\frac{1180 * 0.25}{300}=0.9833<1 \Rightarrow \mathrm{Ok}
$$

In the next time step, $\Delta \mathrm{t}=0.25$, we have a reservoir, an intersection and a pipe which will be closed until $t=6 \mathrm{sec}$. Thus, the boundary condition must be evaluated.

Each pipe has two boundary conditions, upstream and downstream conditions.

- Upstream boundary conditions

$$
\begin{gathered}
\mathrm{H}_{\mathrm{p}}=\mathrm{H}_{0 \mathrm{R}}=130 \mathrm{~m} \\
\mathrm{~V}_{\mathrm{p} \mathrm{o}}=\mathrm{V}_{\mathrm{l}=\mathrm{B}}+\frac{\mathrm{g}}{\mathrm{a}}\left(\mathrm{H}_{\mathrm{P} 。}-\mathrm{H}_{1}\right)-\frac{\mathrm{f}}{2 \mathrm{D}} \Delta \mathrm{t}_{1}^{2}
\end{gathered}
$$

Table 4: head and velocity for pipe 1;

\begin{tabular}{llllllllll}
\hline $\mathrm{X}$ & 0 & 300 & 600 & 900 & 1200 & 1500 & 1800 & 2100 & 2400 \\
\hline $\mathrm{H}$ & 54.8 & 51.2 & 47.6 & 43.9 & 40.3 & 36.6 & 33 & 29.3 & 25.7 \\
$\mathrm{~V} 2$ & 1.86 & 1.86 & 1.86 & 1.86 & 1.86 & 1.86 & 1.86 & 1.86 & 1.86 \\
$\mathrm{X}$ & 2700 & 3000 & 3300 & 3600 & 3900 & 4200 & 4500 & - & - \\
$\mathrm{H}$ & 22 & 18.4 & 17.7 & 11.1 & 7.4 & 3.8 & 0.138 & & \\
$\mathrm{~V} 2$ & 1.86 & 1.86 & 1.86 & 1.86 & 1.86 & 1.86 & 1.86 & & \\
\hline
\end{tabular}

$$
\mathrm{V}_{\mathrm{p} 。}=\mathrm{V}_{1}+0.00829\left(\mathrm{H}_{\mathrm{P}_{\circ}}-\mathrm{H}_{1}\right)-0.015 \mathrm{~V}_{1}^{2}
$$

Then, Vp. is evaluated.

- Boundary conditions at the pipes intersection

In intersection joint, there are six unknown parameters. So we need six equations to find them.

From continuity Eq.,

$$
\begin{aligned}
& \mathrm{Q}_{2}=\mathrm{Q}_{1}+\mathrm{Q}_{3} \Rightarrow \mathrm{V}_{\mathrm{N}, 2} \mathrm{~A}_{2}=\mathrm{V}_{1,1} \mathrm{~A}_{1}+\mathrm{V}_{1,3} \mathrm{~A}_{3} \\
& H_{N, 2}=H_{1,1}=H_{1,3} \\
& H_{1,3}=H
\end{aligned}
$$

When the information come from downstream we should use $\mathrm{C}^{-}$and when the information come from downstream we should use $\mathrm{C}^{+}$,

$$
\begin{aligned}
& \mathrm{C}^{-}:-\frac{\mathrm{g}}{\mathrm{a}_{3}} \mathrm{H}_{1,3}+\mathrm{V}_{1,3}=\phi_{\mathrm{R}, 3} \\
& \mathrm{C}^{-}:-\frac{\mathrm{g}}{\mathrm{a}_{1}} \mathrm{H}_{1,1}+\mathrm{V}_{1,1}=\phi_{\mathrm{R}, 1} \\
& \mathrm{C}^{+}: \frac{\mathrm{g}}{\mathrm{a}_{2}} \mathrm{H}_{\mathrm{N}, 2}+\mathrm{V}_{\mathrm{N}, 2}=\phi_{\mathrm{R}, 2}
\end{aligned}
$$

From Eq. 26-31,

Also,

$$
\mathrm{H}=\frac{\phi_{\mathrm{R}, 2} \mathrm{~A}_{2}-\phi_{\mathrm{R}, 1} \mathrm{~A}_{1}-\phi_{\mathrm{R}, 3} \mathrm{~A}_{3}}{\mathrm{~g}\left(\frac{\mathrm{A}_{1}}{\mathrm{a}_{1}}+\frac{\mathrm{A}_{2}}{\mathrm{a}_{2}}+\frac{\mathrm{A}_{3}}{\mathrm{a}_{3}}\right)}
$$

$$
\begin{aligned}
& \mathrm{V}_{\mathrm{l}, 3}=\phi_{\mathrm{R}, 3}+\frac{\mathrm{g}}{\mathrm{a}_{3}} \mathrm{H} \\
& \mathrm{V}_{1,1}=\phi_{\mathrm{R}, 1}+\frac{\mathrm{g}}{\mathrm{a}_{1}} \mathrm{H} \\
& \mathrm{V}_{\mathrm{N}, 2}=\phi_{\mathrm{R}, 2}-\frac{\mathrm{g}}{\mathrm{a}_{2}} \mathrm{H}
\end{aligned}
$$

The pipes have low slope and, sin $\alpha$ is very small and will be ignored.

From Eq. 9.c and 11.c,

$$
\begin{aligned}
& \phi_{\mathrm{R}, 3}=-\frac{\mathrm{g}}{\mathrm{a}_{3}} \mathrm{H}_{\mathrm{R}, 3}+\mathrm{V}_{\mathrm{R}, 3}-\frac{\mathrm{f}_{3}}{2 \mathrm{D}_{3}} \mathrm{~V}_{\mathrm{R}, 3}^{2} \Delta \mathrm{t} \\
& \phi_{\mathrm{R}, 3}=-0.00831\left(\mathrm{H}_{\mathrm{R}, 3}\right)+\mathrm{V}_{\mathrm{R}, 3}-0.00693 \mathrm{~V}_{\mathrm{R}, 3}^{2}
\end{aligned}
$$


and

$$
\begin{aligned}
& \phi_{R, 1}=-0.00831\left(\mathrm{H}_{R, 1}\right)+\mathrm{V}_{\mathrm{R}, 1}-0.0107 \mathrm{~V}_{\mathrm{R}, 1}^{2} \\
& \phi_{\mathrm{R}, 2}=-0.00831\left(\mathrm{H}_{\mathrm{R}, 2}\right)+\mathrm{V}_{\mathrm{R}, 2}-0.015 \mathrm{~V}_{\mathrm{R}, 2}^{2}
\end{aligned}
$$

For VR, VL, HR, HL, we have,

$$
\begin{aligned}
& \mathrm{V}_{\mathrm{R}, 3}=\frac{\mathrm{V}_{\mathrm{i}, 3}^{\mathrm{n}}-\mathrm{a}_{3}\left(\mathrm{~V}_{\mathrm{i}, 3}^{\mathrm{n}}-\mathrm{V}_{\mathrm{i}+1,3}^{\mathrm{n}}\right) \Delta \mathrm{t} / \Delta \mathrm{x}}{1+\left(\mathrm{V}_{\mathrm{i}, 3}^{\mathrm{n}}-\mathrm{V}_{\mathrm{i}+1,3}^{\mathrm{n}}\right) \Delta \mathrm{t} / \Delta \mathrm{x}} \\
& \mathrm{H}_{\mathrm{R}, 3}=\mathrm{H}_{\mathrm{i}, 3}^{\mathrm{n}}-\left(\mathrm{V}_{\mathrm{R}, 3}+\mathrm{a}_{3}\right)\left(\mathrm{H}_{\mathrm{i}, 3}^{\mathrm{n}}-\mathrm{H}_{\mathrm{i}+1,3}^{\mathrm{n}}\right) \Delta \mathrm{t} / \Delta \mathrm{x} \\
& \mathrm{V}_{\mathrm{R}, \mathrm{1}}=\frac{\mathrm{V}_{\mathrm{i}, 1}^{\mathrm{n}}-\mathrm{a}_{1}\left(\mathrm{~V}_{\mathrm{i}, 1}^{\mathrm{n}}-\mathrm{V}_{\mathrm{i}+1,1}^{\mathrm{n}}\right) \Delta \mathrm{t} / \Delta \mathrm{x}}{1+\left(\mathrm{V}_{\mathrm{i}, 1}^{\mathrm{n}}-\mathrm{V}_{\mathrm{i}+1,1}^{\mathrm{n}}\right) \Delta \mathrm{t} / \Delta \mathrm{x}} \\
& \mathrm{H}_{\mathrm{R}, 1}=\mathrm{H}_{\mathrm{i}, 1}^{\mathrm{n}}-\left(\mathrm{V}_{\mathrm{R}, 1}+\mathrm{a}_{1}\right)\left(\mathrm{H}_{\mathrm{i}, 1}^{\mathrm{n}}-\mathrm{H}_{\mathrm{i}+1,1}^{\mathrm{n}}\right) \Delta \mathrm{t} / \Delta \mathrm{x} \\
& \mathrm{V}_{\mathrm{R}, 2}=\frac{\mathrm{V}_{\mathrm{i}, 2}^{\mathrm{n}}-\mathrm{a}_{2}\left(\mathrm{~V}_{\mathrm{i}, 2}^{\mathrm{n}}-\mathrm{V}_{\mathrm{i}+1,2}^{\mathrm{n}}\right) \Delta \mathrm{t} / \Delta \mathrm{x}}{1+\left(\mathrm{V}_{\mathrm{i}, 2}^{\mathrm{n}}-\mathrm{V}_{\mathrm{i}+1,2}\right) \Delta \mathrm{t} / \Delta \mathrm{x}} \\
& \mathrm{H}_{\mathrm{R}, 2}=\mathrm{H}_{\mathrm{i}, 2}^{\mathrm{n}}-\left(\mathrm{V}_{\mathrm{R}, 2}+\mathrm{a}_{2}\right)\left(\mathrm{H}_{\mathrm{i}, 2}^{\mathrm{n}}-\mathrm{H}_{\mathrm{i}+1,2}^{\mathrm{n}}\right) \Delta \mathrm{t} / \Delta \mathrm{x}
\end{aligned}
$$

- Valve closing

Valve is closed in $6 \mathrm{sec}$ and the rate of closing is showed by Table 5 .

$\tau=1($ at $t=0)$ means that the valve is opened and $\tau=0$ (at $\mathrm{t}=6 \mathrm{sec}$ ) means that the valve is closed.

Fig. 6 shows the curve of $t-\tau$.

With trend line in Excel program, the Equation of change will be computed.

This Equation is very exact because the regression coefficient is 0.9988 and we can use it for valve work.

Valve Eq. is defined by,

$$
\mathrm{V}=\tau \beta \mathrm{H}^{0.5} \Rightarrow \mathrm{V}=0.212 \tau \mathrm{H}^{0.5}
$$

This Equation has 2 unknown parameters. Then we need another Equation;

$$
\mathrm{V}_{\mathrm{P}}^{\mathrm{n}+1}=\mathrm{C}_{3}-\mathrm{C}_{2} \mathrm{H}_{\mathrm{p}}^{\mathrm{n}+1} \Rightarrow \mathrm{H}_{\mathrm{p}}^{\mathrm{n}+1}=\frac{\mathrm{C}_{3}-\mathrm{V}_{\mathrm{P}}^{\mathrm{n}+1}}{\mathrm{C}_{2}}
$$

Table 5: Valve open in second 0 and close in 6 second

\begin{tabular}{llll}
\hline $\mathrm{t}$ & $\tau \%$ & $\mathrm{t}$ & $\tau \%$ \\
\hline 0 & 1 & 3.6 & 0.43 \\
0.6 & 0.96 & 4.2 & 0.27 \\
1.2 & 0.91 & 4.8 & 0.16 \\
1.8 & 0.84 & 5.4 & 0.06 \\
2.4 & 0.75 & 6 & 0 \\
3 & 0.61 & & \\
\hline
\end{tabular}

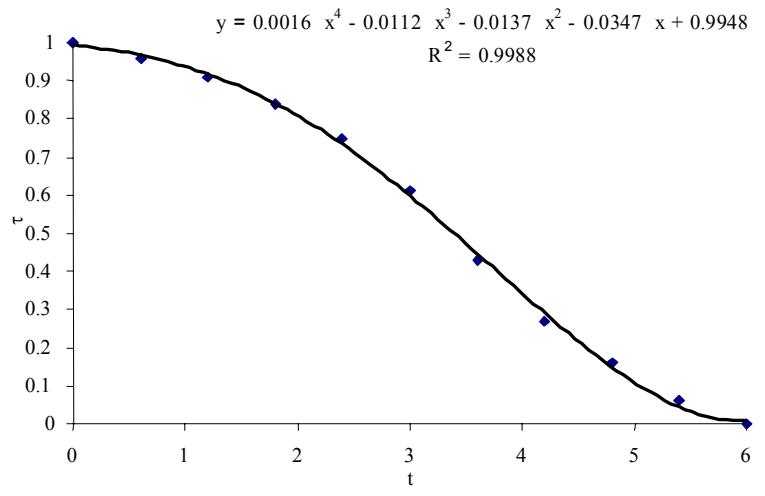

Fig. 6: Valve situation

$$
\begin{aligned}
& \mathrm{C}_{2}=\frac{\mathrm{g}}{\mathrm{a}_{1}} \\
& \mathrm{C}_{3}=\mathrm{V}_{\mathrm{A}}^{\mathrm{n}}+\mathrm{C}_{3} \mathrm{H}_{\mathrm{A}}^{\mathrm{n}}-\frac{\mathrm{f}_{1}}{2 \mathrm{D}_{1}} \Delta \mathrm{t}\left(\mathrm{V}_{\mathrm{A}}^{\mathrm{n}}\right)^{2} \\
& \mathrm{C}_{3}=\mathrm{V}_{\mathrm{A}}^{\mathrm{n}}+0.00831 \mathrm{H}_{\mathrm{A}}^{\mathrm{n}}-0.0107\left(\mathrm{~V}_{\mathrm{A}}^{\mathrm{n}}\right)^{2}
\end{aligned}
$$

Thus;

\begin{tabular}{|c|c|c|c|c|c|c|c|c|c|}
\hline \multicolumn{3}{|c|}{ Reservoir } & & & & & & & Int. Joint \\
\hline & \multicolumn{9}{|c|}{ No.2 } \\
\hline$X=$ & 0 & 300 & 600 & 900 & 1200 & 1500 & 1800 & 2100 & 2400 \\
\hline $\mathrm{H}=$ & 130.00 & 120.60 & 111.21 & 101.82 & 92.43 & 83.03 & 73.64 & 64.24 & 54.85 \\
\hline $\mathrm{V}=$ & 2.174 & 2.174 & 2.174 & 2.174 & 2.174 & 2.174 & 2.174 & 2.174 & 2.174 \\
\hline $\mathrm{H}=$ & & 129.86 & 120.46 & 111.07 & 101.68 & 92.29 & 82.89 & 73.50 & 64.10 \\
\hline$V=$ & & 2.174 & 2.174 & 2.174 & 2.174 & 2.174 & 2.174 & 2.174 & 2.6372 \\
\hline $\mathrm{H}=$ & & 111.38 & 101.99 & 92.60 & \begin{tabular}{|l|}
83.20 \\
\end{tabular} & 73.81 & 64.41 & 55.02 & \\
\hline $\mathrm{V}=$ & & 3.1828 & 3.1046 & 3.0266 & 2.9485 & 2.8704 & 2.7923 & 2.7142 & \\
\hline
\end{tabular}

$$
\begin{aligned}
& \mathrm{V}_{\mathrm{PN}}=-\frac{\mathrm{C}_{4}}{2}+\left[\left(\frac{\mathrm{C}_{4}}{2}\right)^{2}+\mathrm{C}_{3} \mathrm{C}_{4}\right]^{0.5} \\
& \mathrm{C}_{4}=\frac{\tau^{2} \beta^{2}}{\mathrm{C}_{2}}=\frac{\tau^{2} * 0.212^{2}}{0.00831}=5.41 \tau^{2}
\end{aligned}
$$

End of pipe 3, until $t<6 \mathrm{sec}$, because of pump, works similar to a closed valve.

$$
\mathrm{V}_{\mathrm{P}}^{\mathrm{n}+1}=0 \Rightarrow \mathrm{H}_{\mathrm{P}}^{\mathrm{n}+1}=\frac{\mathrm{C}_{3}}{\mathrm{C}_{2}}
$$

- Boundary condition after $\mathrm{t}=6 \mathrm{sec}$

Instantly, after 6 sec, pump is started, whereas the valve at the end of pipe 1 has been closed.

Then we have a problem with two reservoirs and one pump.

Fig. 7: Calculations of pipe 1 at $\mathrm{t}=0$,

Now we should calculate the new boundary conditions. Pump has a characteristic curve,

$$
\mathrm{H}=\mathrm{a}_{\circ}+\mathrm{a}_{1} \mathrm{Q}+\mathrm{a}_{2} \mathrm{Q}^{2} \Rightarrow \mathrm{H}=240+20 \mathrm{Q}-300 \mathrm{Q}^{2}
$$


Pump is located in downstream of reservoir, therefore $\mathrm{V}$ is negative,

$$
\begin{aligned}
& \Delta H=H_{P}-H_{R} \Rightarrow H_{P}=H_{R}+a_{\circ}++a_{1} Q++a_{2} Q^{2} \\
& \Rightarrow \mid \begin{array}{l}
H_{P}=H_{R}+a_{\circ}-a_{1} A V_{P}+a_{2} A^{2} V_{P}^{2} \\
C^{+}: \frac{g}{a} H_{P}+V_{P}=\phi_{L} \Rightarrow H_{P}=\frac{g}{a}\left(\phi_{L}-V_{P}\right)
\end{array} \\
& \frac{g}{a}\left(\phi_{L}-V_{P}\right)=H_{R}+240-20 A V_{P}-300 A^{2} V_{P}^{2} \\
& -2.22 V_{P}+118.56 V_{P}+\left(250-120.28 \phi_{L}\right)=0
\end{aligned}
$$

In this Eq.,

$$
\phi_{\mathrm{L}}=0.00821 \mathrm{H}_{\mathrm{L}}+\mathrm{V}_{\mathrm{L}}-0.00693 \mathrm{~V}_{\mathrm{L}}^{2}
$$

and VL, HL are,

$$
\begin{aligned}
& \mathrm{V}_{\mathrm{L}}=\frac{\mathrm{V}_{\mathrm{i}}^{\mathrm{n}}-\mathrm{a}\left(\mathrm{V}_{\mathrm{i}}^{\mathrm{n}}-\mathrm{V}_{\mathrm{i}-1}^{\mathrm{n}}\right) \Delta \mathrm{t} / \Delta \mathrm{x}}{1+\left(\mathrm{V}_{\mathrm{i}}^{\mathrm{n}}-\mathrm{V}_{\mathrm{i}-1}^{\mathrm{n}}\right) \Delta \mathrm{t} / \Delta \mathrm{x}} \\
& \mathrm{H}_{\mathrm{L}}=\mathrm{H}_{\mathrm{i}}^{\mathrm{n}}-\left(\mathrm{V}_{\mathrm{L}}+\mathrm{a}\right)\left(\mathrm{H}_{\mathrm{i}}^{\mathrm{n}}-\mathrm{H}_{\mathrm{i}-1}^{\mathrm{n}}\right) \Delta \mathrm{t} / \Delta \mathrm{x}
\end{aligned}
$$

Thus, $\mathrm{Vp}$ is evaluated from Eq. 52.

\section{RESULTS AND DISCUSSION}

We have used Microsoft Excel for calculation. All of the equations are explicit and solve by Excel easily. This software not only can get function, but also, can draw graphical output.

For solving of this program; Initial conditions are located in first line and with derived Equations and conditions of other points will calculated by characteristic method.

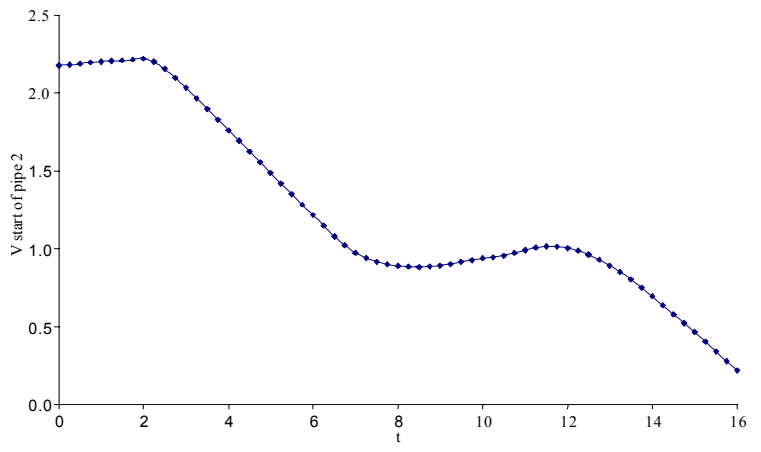

Fig. 8: Velocity changes at the start of pipe 2

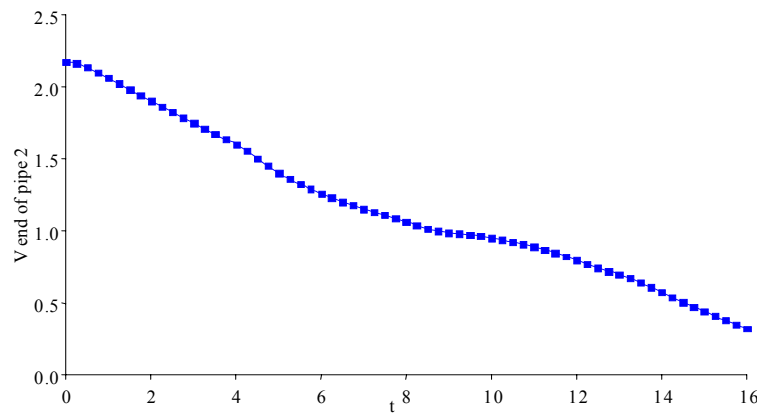

Fig. 9: Velocity changes at the end of pipe 2

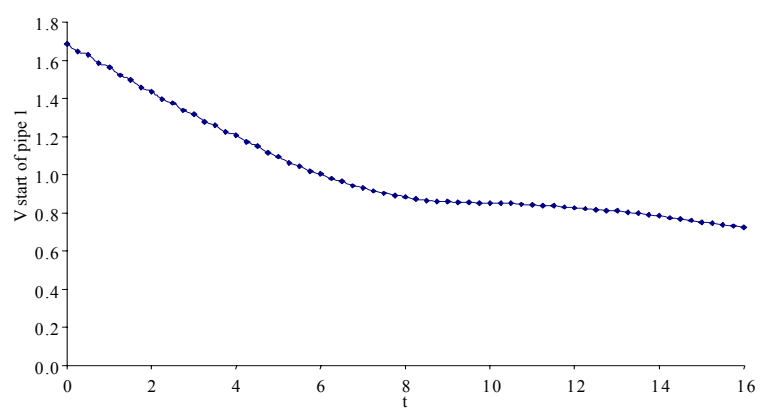

Fig. 10: Velocity changes at the start of pipe 1

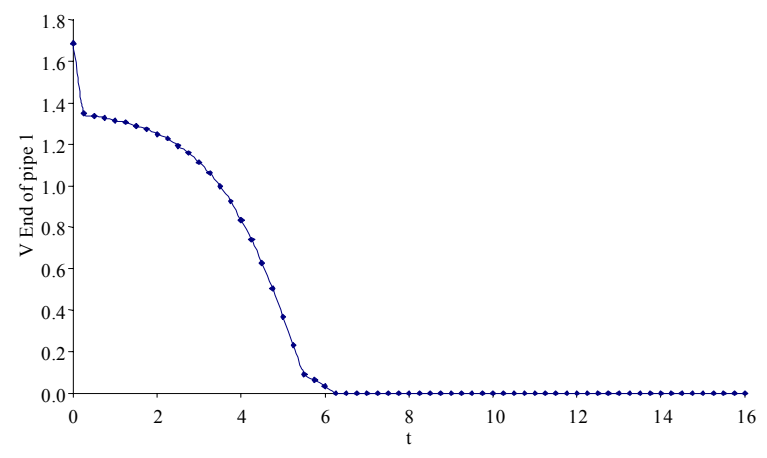

Fig. 11: Velocity changes at the end of pipe 1

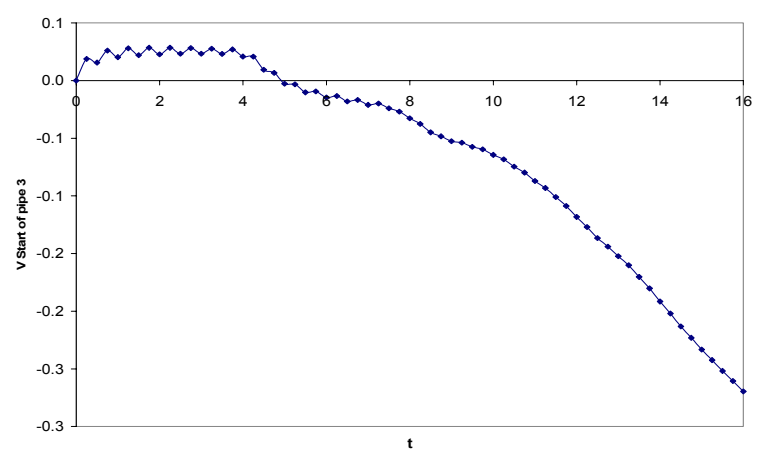

Fig. 12: Velocity changes at the start of pipe 3 


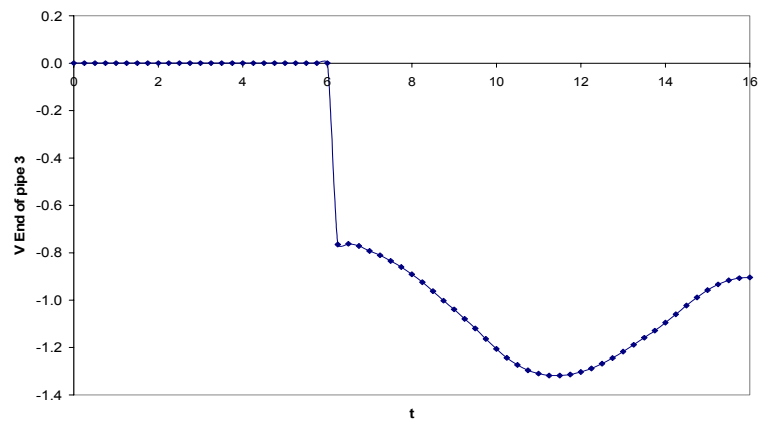

Fig. 13: Velocity changes at the end of pipe 3

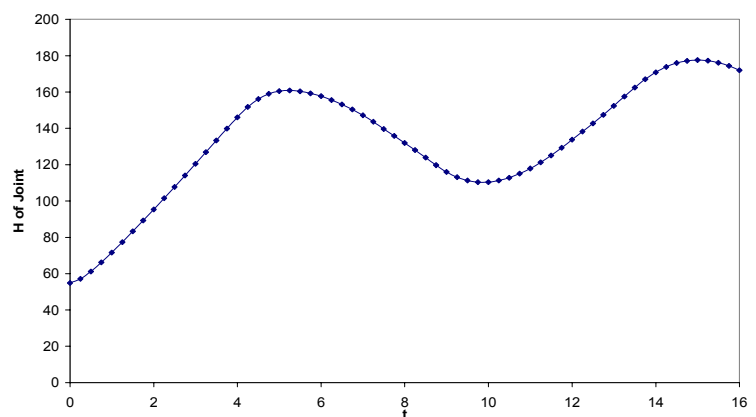

Fig. 14: Head changes at the Intersection Joint

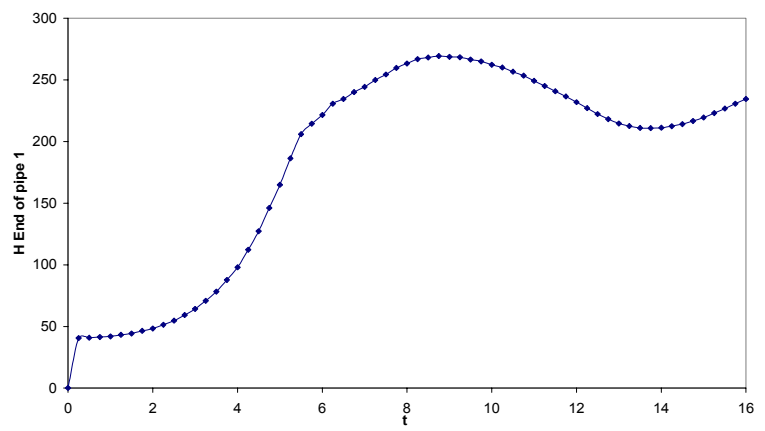

Fig. 15: Head changes at the end of pipe 1

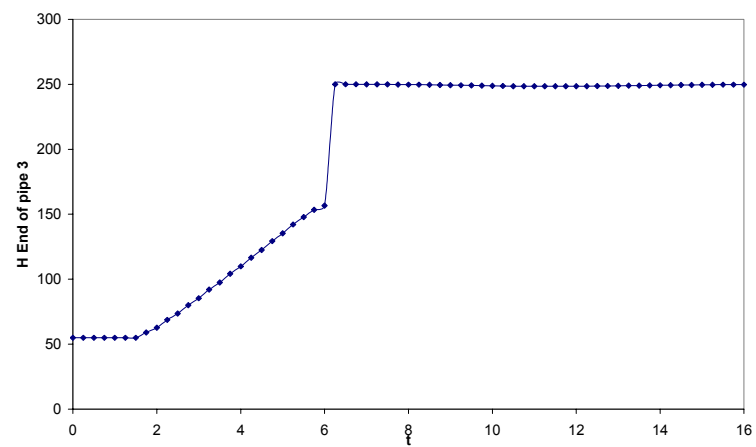

Fig. 16: Head changes at the end of pipe 3

Calculations of pipe 1 at $\mathrm{t}=0$, are shown in Fig 7 .
As it can be seen in the following figures, after second 6 , when the pipe is closed, some variations will be happened.

Valve closing has no very affection on water velocity at end of pipe 2 and velocity changing at the start and end of pipe 2, shows that the water hammer has not been happened (Fig 8 and Fig 9).

Velocity changing at the start of pipe 1 , shows that the water hammer has not been happened (Fig 10).

Velocity changing at the end of pipe 1 , shows that the water hammer is near to be happened (Fig 11).

Velocity changing at the start and end of pipe 3 shows that the water hammer has been happened (Fig 12 and Fig 13).

Compare of water head in Fig 14 and Fig 15 and Fig 16 , approves the water hammer in pipe 3 .

\section{CONCLUSION}

In the present study, we could consider water hammer by characteristic method for pipe flow and get some formula. We can make this method public, for other problems.

In the pipe 1 , when the valve, at $t=6$ is closed, velocity of its end, gradually goes to 0 , Fig 11 .

But, when the valve, at $\mathrm{t}=6$ is closed, velocity of its start, is not 0 , then water hammer is occurred, Fig 10. Also these changes are in heads of end of pipe 1 Fig 15.

In Fig 12 at the start of pipe 3, a small turbulence has been seen. This turbulence has been caused by the step of computing. For omit of it, the step of $t$ and $x$ should be smaller.

After $t=6$, we can see the change in velocity and head of water in pipe. These changed spread in pipe after $6 \mathrm{sec}$ than valve closed.

For preventing of water hammer defects, is recommended that valves should be open or closed slowly.

\section{REFERENCES}

1. Apelt, C.J., 1986. Water Hammer Academic session. University of Queensland. Australia. http://search.informit.com.au/fullText;dn=5082323 31251828;res=IELENG

2. Banihashemi A., 2002. Computational Hydraulic Academic session, University of Tehran, Iran. http://eng.ut.ac.ir/Fa/CIV/bani-hashemi/

3. Santosh K.G., 2004. Irrigation Engineering and Hydraulic Structures. 18th edition. Khana Publisher, Delhi. www.ptu.ac.in/syalbe/ce-02.pdf

4. Richard H. French, 1994. Open-Channel Hydraulic, 4th edition. McGraw-Hill, Inc. USA. http://www.civil.iitb.ac.in/153-ug/ref.html 